\title{
Program Executive Officer Aviation, Major Milestone Reviews: Lessons Learned Report
}

Scott Reed

Kathryn Ambrose Sereno

September 2010

TECHNICAL REPORT

CMU/SEI-2010-TR-006

ESC-TR-2010-006

Acquisition Support Program

Unlimited distribution subject to the copyright.

http://www.sei.cmu.edu

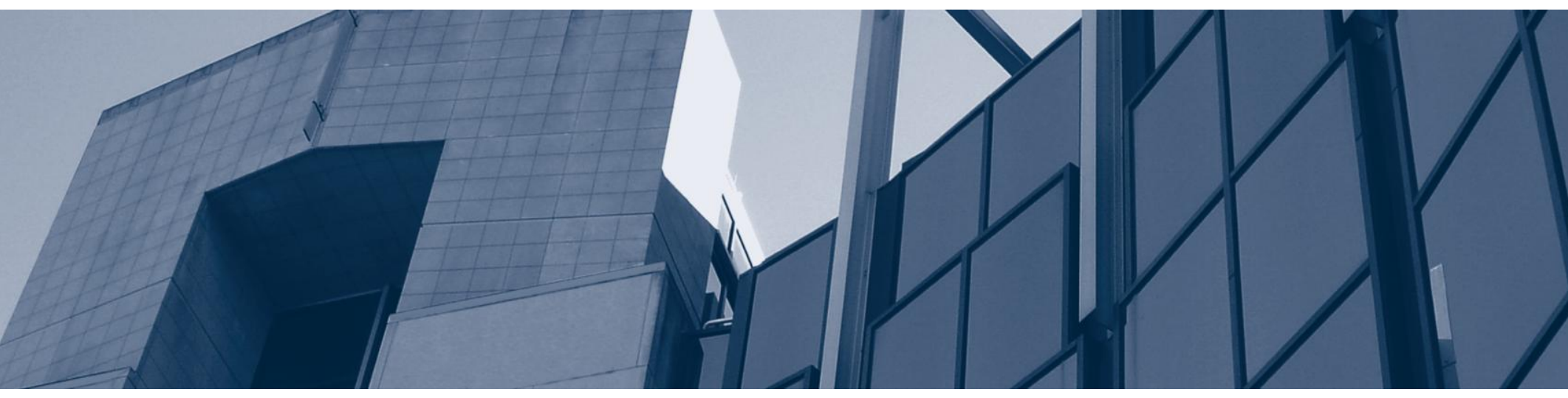


This report was prepared for the

SEI Administrative Agent

$\mathrm{ESC} / \mathrm{XPK}$

5 Eglin Street

Hanscom AFB, MA 01731-2100

The ideas and findings in this report should not be construed as an official DoD position. It is published in the interest of scientific and technical information exchange.

This work is sponsored by the U.S. Department of Defense. The Software Engineering Institute is a federally funded research and development center sponsored by the U.S. Department of Defense.

Copyright 2010 Carnegie Mellon University.

\section{NO WARRANTY}

THIS CARNEGIE MELLON UNIVERSITY AND SOFTWARE ENGINEERING INSTITUTE MATERIAL IS FURNISHED ON AN “AS-IS” BASIS. CARNEGIE MELLON UNIVERSITY MAKES NO WARRANTIES OF ANY KIND, EITHER EXPRESSED OR IMPLIED, AS TO ANY MATTER INCLUDING, BUT NOT LIMITED TO, WARRANTY OF FITNESS FOR PURPOSE OR MERCHANTABILITY, EXCLUSIVITY, OR RESULTS OBTAINED FROM USE OF THE MATERIAL. CARNEGIE MELLON UNIVERSITY DOES NOT MAKE ANY WARRANTY OF ANY KIND WITH RESPECT TO FREEDOM FROM PATENT, TRADEMARK, OR COPYRIGHT INFRINGEMENT.

Use of any trademarks in this report is not intended in any way to infringe on the rights of the trademark holder.

Internal use. Permission to reproduce this document and to prepare derivative works from this document for internal use is granted, provided the copyright and "No Warranty" statements are included with all reproductions and derivative works.

External use. This document may be reproduced in its entirety, without modification, and freely distributed in written or electronic form without requesting formal permission. Permission is required for any other external and/or commercial use. Requests for permission should be directed to the Software Engineering Institute at permission@sei.cmu.edu.

This work was created in the performance of Federal Government Contract Number FA8721-05-C-0003 with Carnegie Mellon University for the operation of the Software Engineering Institute, a federally funded research and development center. The Government of the United States has a royalty-free government-purpose license to use, duplicate, or disclose the work, in whole or in part and in any manner, and to have or permit others to do so, for government purposes pursuant to the copyright license under the clause at 252.227-7013.

For information about SEI publications, please visit the library on the SEI website (www.sei.cmu.edu/library). 


\section{Table of Contents}

Contributors $\quad$ iii

$\begin{array}{lc}\text { Abstract } & \text { v }\end{array}$

1 Introduction $\quad 1$

1.1 Context 1

1.2 Background 1

1.3 Purpose 1

1.4 Approach 2

1.5 Audience 2

1.6 How to Use the Lessons Learned in this Document 2

2 Lessons Learned $\quad 3$

2.1 General Lessons Learned 3

2.2 Programmatic Lessons Learned $\quad 6$

2.3 Documentation Lessons Learned $\quad 8$

2.4 Army Systems Acquisition Review Council (ASARC) and Defense Acquisition Board (DAB) Processes Lessons Learned 10

2.5 Logistics and Support Lessons Learned 13

2.6 Technical/Engineering Lessons Learned 16

$\begin{array}{lll}2.7 & \text { Test and Evaluation Lessons Learned } & 18\end{array}$

2.8 Source Selection and Evaluation Lessons Learned-Attack Reconnaissance Helicopter (ARH)

$\begin{array}{lr}\text { Appendix A: Longbow Apache Overview } & 25\end{array}$

\begin{tabular}{ll} 
Appendix B: & Armed Reconnaissance Helicopter Overview \\
\hline
\end{tabular}

Appendix C: $\quad$ UH-60M Black Hawk Executive Summary $\quad 31$

Appendix D: Raven Unmanned Aerial System AT\&L Article: "Acquisition in the Fast Lane-The Small Unmanned Aerial Vehicle (SUAV) Product Office" 33

$\begin{array}{lr}\text { Appendix E: Acronyms } & 37\end{array}$ 
CMU/SEI-2010-TR-006 | ii 


\section{Contributors}

\section{Apache Longbow-AH-64 (Block III)}

Bob Grewe, Deputy Project Manager, Apache Block III (AB3)

Paul T. Keil, (Westar) Apache Block III (AB3) Team

\section{Armed Reconnaissance Helicopter (ARH)}

Mark Kaskey, Deputy Project Manager

Mark Peterson, Chief, Technical Division

\section{Black Hawk UH-60M}

Forest Collier, Test IPT Lead

Dmitri Gerousis, Integrated Manufacturing Sub-IPT Lead

Bill Hanks, SE Sub-IPT Lead

Mike Herbst, Deputy Project Manager

Heather Hone, Mission Equipment Package (MEP) Sub-IPT Lead

LTC Robert "Chip" Lunn, Product Manager

Eric Martin, Air Vehicle Sub-IPT Lead

Kelvin Nunn, M Ch. Engineer

Scott Silies, M Baseline Project Engineer

John T. Smith, Logistics IPT Lead

Roy Trousdale, Business Integrated Product Team (IPT) Lead

\section{Raven RQ-11 Unmanned Aerial System}

William R. (Bobby) Ellis Jr., Product Manager 


\section{Abstract}

This report documents ideas and recommendations for improving the overall acquisition process and presents the actions taken by project managers in several programs to develop, staff, and obtain approval for their systems. This report contains information on the decision briefings and lessons learned, and describes issues encountered and the recommendations regarding the actual processes that were followed. Finally, this report includes checklists of required actions that will assist new and existing Program Management Offices (PMOs) as they prepare for milestone reviews. 


\section{Introduction}

\subsection{Context}

Although the systems acquisition life-cycle process is well known and accepted by the systems acquisition community, it does not necessarily support time-urgent requirements that result in a new start. ${ }^{1}$ Statute requirements drive much of the process and are not a prescription to circumventing that process. Included in this document are ideas and recommendations that can make or could have made the overall acquisition process easier, quicker, and less repetitive.

Based on the experience of the product managers (PMs), this report prescribes insights and lessons learned from every major facet of a normal acquisition program. The experiences outlined in this report may not reflect those of other PMs, and their programs may not pose the same challenges and requirements as others. However, the intent is to provide information in an effort to (1) prevent someone from repeating past mistakes and (2) set the conditions to capitalize on past successes.

This report describes the actions taken by the project and product managers to develop, staff, and obtain approval for their systems. The report contains information on the decision briefings and lessons learned, and also describes issues encountered and the recommendations regarding the actual processes the PMs followed. Finally, the report includes checklists of required actions (garnered from lessons learned reports and recorded interviews) that will be of assistance during milestone review preparation.

\subsection{Background}

At the direction of the Program Executive Office (PEO) Aviation, this report provides an accounting of the lessons learned by Longbow Apache Block III, Armed Reconnaissance Helicopter, Raven, UH-60M Modernization Product Office, and Warrior. These lessons learned were accomplished during the milestone review process, which took place between January 2005 and April 2007 and represent one ACAT I and two ACAT II unmanned aerial systems.

\subsection{Purpose}

This report is intended to provide usable and actionable information for new-start and existing Program Management Offices (PMOs) that are working through the milestone review process. The intent of this report is not to provide a "how to" in lieu of the published acquisition process; rather, the report provides insights and lessons learned to benefit those who are working through the acquisition process.

A new start is a program not previously justified and appropriated by Congress through the normal budget process. 


\subsection{Approach}

In researching this report, interviews were conducted with key government and contractor support personnel from the represented project offices that were responsible for milestone preparation and active briefing of key government official decision makers. Information was also extracted from after action reports, articles published in acquisition periodicals, and lessons learned reports. ${ }^{2}$

\subsection{Audience}

This document is focused on the needs of the PEO Aviation and its project offices, but also has application to all Department of Defense (DoD) acquirers, a community that typically acquires software-intensive systems. It is believed that the lessons learned information is applicable regardless of the type of system being acquired.

\subsection{How to Use the Lessons Learned in this Document}

Section 2, Lessons Learned, is organized by

- functional area context (e.g., logistics)

- a table of program observations and lessons learned checklist for milestone preparation

- $\quad$ source selection and evaluation lessons learned

The lists were compiled from the interviews and extraction of processes and activities from both the lessons learned and after action reports. These lists will be useful during preparation and participation in briefings and milestone reviews.

2 The government decision makers were members of the Department of Defense/Army. 


\section{Lessons Learned}

\subsection{General Lessons Learned}

The observations included in this subsection (Section 2.1) do not fit within a particular domain. However, since they are overarching and foundational to the remaining content in this report, they are sufficiently important to include here.

When doing concurrent staffing with milestone documents, which are all moving toward review at different speeds, it is easy for processes to get out of sync. As you move forward, it is important to keep these processes synchronized. A "Smart Book" is a key tool for briefing Army leadership and tracking changes over time.

\section{Lessons Learned Checklist}

$\square \quad$ Experience and maturity are the key qualifiers for staffing and keeping it small.

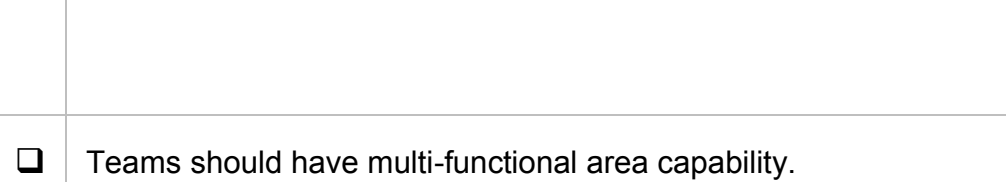

\begin{tabular}{|l|l|} 
\\
\\
\\
\hline$\square$ \\
\hline
\end{tabular} epresses in sync on concurrent staffing of milestone documents moving at varying speeds. At times achieving total document synchronization may prove impossible. Identify the program's critical pacing documents and concentrate efforts on these documents.

- Overcome resistance by developing allies and engaging with them often. Find those allies who have issues and engage them directly (one-on-one). Provide sufficient information when briefing primary staff elements, Army, and the Office of the Secretary of Defense (OSD).

Fully engage with the OSD staff to improve communication and establish and maintain rapport.

F From the very beginning, work to ensure that a DASC at the Army level is assigned to your program.

\section{Program Observations}

The first job for the new team was to assemble the necessary personnel to staff the new PMO.

The team of 30 shared several key traits: driven desire and focus to support the soldier, ability to multi-task, a mature demeanor, 10-plus years of experience in their functional areas, and a willingness to work long hours and travel.

Maintain a Smart Book or a consistent set of slides. As you make changes and decisions quickly, it is important to update these slides.

Despite repeated efforts to highlight this with Army leadership, we did not have a dedicated Department of the Army staff coordinator (DASC). The DASC performs many functions, including serving as the acting deputy in the Assistant Secretary of the Army (Acquisition, Logistics, and Technology) (ASA(ALT)) organization. 
- Track critical decisions so that continuous impact is made during the process and leadership remains informed.

口 Cross-walk all Key Performance Parameters (e.g., survivability and force protection) from the capability development document (CDD) to other salient Milestone B documents (e.g., the acquisition strategy report, test and evaluation master plan). This will help you to comply with the Joint Capabilities Integration and Development System (JCIDS) process.

- Conduct working integrated product team (WIPT) meetings at least every six months. Integrating integrated product teams (IIPTs) and overarching integrated product teams (OIPTs) will be convened as requested by OSD to inform new OSD personnel and overcome "decay rate" in OSD's understanding of the program.

Conduct recurring WIPTs to brief new attendees on salient aspects of the acquisition strategy and program schedule. Acquisition strategy report (ASR) changes (e.g., lot configuration differences and time between lots facilitating desired operational test events) should be briefed to Army Test and Evaluation Command (ATEC) and the Deputy Under Secretary of the Army for Operations Research (DUSA-OR) leadership prior to requesting Director of Operational Test and Evaluation (DOT\&E) acceptance.

Pre-brief the high-ranking officers in G-8, G-3, ASA(ALT) and the Joint Chiefs of Staff Functional Capabilities Board (JCB) (part of pre-Joint Requirements Oversight Council [JROC] briefing path). Especially crucial are briefings to high-ranking members of the Defense Acquisition Board (DAB) who may not have prior understanding of your program from a macro point of view.

Conduct senior officer briefings. These briefings are critical to ensure acquisition program baseline (APB) and Joint Requirements Oversight Council memorandum (JROCM) approval of the CDD are in synchronization at Milestone $B$ in order to sign an acquisition decision memorandum (ADM) and, more importantly, a System Development Demonstration (SDD) contract. Doing this will avoid work stoppages at the contractor's production line.

- Maintain continuous interaction with OSD AT\&L Land Warfare; this is extremely important since this organization is involved with numerous programs. 
$\square \quad$ Continuously coordinate to prevent decay rate in understanding the various aspects of a new program. This is critical for a program that is undergoing a decision review. To keep functional experts in lock-step with the SDD phase leading to Milestone C, it is crucial to coordinate among Army and OSD Office of the General Counsel, Policy, and DOT\&E officials.

The Army Deputy Chief of Staff (G8, Program Analysis and Evaluation) and the OSD Cost Analysis Improvement Group (CAIG) must validate affordability assessments, including 20-year operation and support (O\&S) cost estimates, which should be reflected in the Army cost position. Test and evaluation master plan (TEMP), cost estimates, and policy issues are symbiotic in that a change in one area will produce a profound effect on a different functional area. 


\subsection{Programmatic Lessons Learned}

The APB outlines how the system will be procured and maintained throughout its life cycle. It contains a synopsis of many of the other documents that are developed for the milestone decision. The APB is developed after most of the other documentation is finalized; however, it must be prepared before system development and demonstration, production and deployment, and full rate production.

A program's acquisition strategy outlines the business and technical management approaches that are designed to achieve program objectives within the resource constraints imposed. Pursuant to Army Regulation (AR) 70-1, the acquisition strategy is based upon an approved requirement (e.g., Capability Development Document, Capability Production Document). The acquisition strategy

- is the framework for planning, directing, contracting for, and managing a program

- outlines activities that are essential for program success, including a master schedule for research, development, test, production, fielding, modification, post-production management (i.e., sustainment), and demilitarization

The Acquisition Strategy Report is a recurring report that keeps higher management appraised of the execution of the program acquisition strategy.

\section{Lessons Learned Checklist}

Ensure that all points of contact (POCs) are aware when new versions of the APB are distributed.

Provide updates for the APB in the cost analysis reporting system file. Do this for everything, including initial staffing.

\section{Program Observations}

Final estimates for funding requirements in the Army cost position differed greatly from the initial budget profiles developed in the Analysis of Alternatives (AoA) and from market research. Keeping the $G 8$ in the loop throughout the budget process, as a member of the Army Cost Review Board (CRB), enabled the Army to perform the required affordability analysis in a timely manner and identify reprogramming actions that addressed specific funding shortfalls. This prevented potential unfavorable affordability assessments later in the Milestone Review process.

What does the ASR reflect? At Milestone $B$ and the Restructure, the ASR reflected only a general acknowledgement that a follow-on program was allowed in the ASR. At Milestone $\mathrm{C}$, the expectation was changed to reflect greater detail. This caused one of the first major rewrites when we used the same level of detail from the Milestone B and Restructure ASRs. 


\section{Lessons Learned Checklist}

Ensure that the contract for the APB should be well defined.

Ensure that prospective budget profiles are provided to the DCS G8 at all stages of the program. This will enable the Army to perform required affordability analysis in a timely manner and identify reprogramming actions that address specific funding shortfalls.

\section{Program Observations}

The APIB is a contract between the PM and the defense acquisition executive (DAE) regarding cost, schedule, and performance of the system being acquired.

Providing prospective budget profiles to DCS G8 at all stages of the program may enable the Army to perform required affordability analysis in a timely manner and identify reprogramming actions that address specific funding shortfalls. 


\subsection{Documentation Lessons Learned}

\section{Context}

As part of the milestone review budget process, the PMO prepares the Cost Analysis Requirements Document (CARD) and Program Office Estimate (POE), the Deputy Assistant Secretary of the Army for Cost and Economics prepares a Component Cost Analysis (CCA), and OSD CAIG prepares an Independent Cost Estimate (ICE). Army Cost Position (ACP) provides an analysis of the cost risk area; technical, schedule, and requirements creep; and cost-estimating uncertainty. These documents require sufficient data to accurately estimate the cost of each alternative platform and reflect the risk confidence levels.

\section{Lessons Learned Checklist}

Sanitize the CARD, POE, CCA, and ACP data to avoid disclosing the proposed approach of each offeror and the number of proposals. This can be accomplished by using codes for the offerors and including additional platforms so that it is not possible to identify the offerors.

Use the Defense Acquisition University website, which provides useful information on all aspects of reporting requirements, including integrated baseline reviews, EVMS, and new program startup workshops.

- Manage as effectively as possible considering that key players continually change.

Estimate the time involved in developing and coordinating key documents.

\section{Program Observations}

To avoid disclosing the proposed approach of each offeror and the number of proposals, the CARD, POE, CCA, and ACP should use sanitized data for each alternative platform and include data/estimates for additional platforms in the marketplace.

It is difficult to anticipate the documentation timelines that are necessary to "get a pass" from some organizations, such as the CAIG and DOT\&E.

Due to the length of the process, the Apache Block III (AB3) specific knowledge "decay rate" or organizational "face changes" caused numerous re-briefs. We were often revisiting previously closed issues because a key player was changed within the process chain.

Document approvals accounted for the greatest PMO resource investments. Key documents included:

- Capabilities Development Document

- Acquisition Strategy Report

- Test and Evaluation Management Plan

- Systems Engineering Plan (SEP)

- Independent Life-Cycle Cost Estimate

- Technology Readiness Assessment (TRA)

- Information Support Plan (ISP) (Clinger Cohen Act compliance) 


\section{Lessons Learned Checklist}

口 Invest the time to brief key Pentagon personnel to secure their support in programming dollars.

\section{Program Observations}

Repeated trips to Washington to brief the $\mathrm{G} 8$ and Army Budget Office personnel are time consuming. However, during program objective memorandum (POM) development activities, champions were secured for the Small Unmanned Air Vehicle program. This ensured daily contact with key personnel and offices within the Pentagon.

Special attention is required when dealing with Army information and interoperability coordination and documentation. This is driven by the fact that Army information is fragmented across Headquarters, Department of the Army (HQDA). Also, information activities can be found in disparate groups, each requiring their own unique information as follows.

- G-3 Information Requirements

- G-6 Acquisition Compliance and Certification

- G-6 Frequency Spectrum Division-NETCOM

- G-6 Architecture Operations Network and Space

The impending Joint Tactical Radio System (JTRS) program had a profound effect on the Apache Block III (AB3) Information documentation. Army and OSD G-6 officials used the program as the "pioneer" to improve interoperability expected to be filled by JTRS when that program reaches maturity. JTRS program turbulence generated a "Moderate Risk" for the AB3 program Net Ready Key Performance Parameter (KPP). 


\subsection{Army Systems Acquisition Review Council (ASARC) and Defense Acquisition Board (DAB) Processes Lessons Learned}

The Army Systems Acquisition Review Council (ASARC) is the Army-level review body for acquisition of all ACAT I/IA programs and other select programs where the Army Acquisition Executive (AAE) is the Milestone Decision Authority (MDA). The ASARC provides a structured forum where issues requiring top-level consideration are presented to senior Army leadership. DODD 5000.1, DODI 5000.02, and AR 70-1 govern the Army's milestone review process. The DAB and Information Technology Acquisition Board (ITAB) are OSD-level forums that operate in much the same manner as the ASARC. The DAB/ITAB and the ASARC differ in the level of their respective memberships and the ACAT level of the programs they review.

The ASARC, DAB, and ITAB are advisory bodies. The council/board recommendations are conveyed to the respective MDA for final decision. In the majority of cases, the MDA is present during these reviews, which preclude additional reviews. The ASA(ALT) chairs the ASARC; the $\mathrm{DAB}$ and ITAB are chaired by the Under Secretary of Defense for Acquisition, Technology and Logistics (USD(AT\&L)).

\section{Lessons Learned Checklist}

Maintain proper communication in an effort to keep the new members educated. This is important because of the frequent rotation of military staffers.

\section{Program Observations}

DA and OSD staff members do a pretty good job of assigning representatives to the programs. However, due to rotations-especially among military members-the PM is constantly educating the staff members.

Due to workload, staff members cannot always remain current on the status of the particular program.

OSD AT\&L staff members are reluctant to conduct IIPT meetings early in the process because they can be time consuming. At the same time they want to "socialize" staff members to strategies and issues and their solutions at the last minute, when there is little time to affect change.

The Army Systems Acquisition Review Council (ASARC) secretary helps to get things through the military department (MILDEP) and the Army Acquisition Executive (AAE).

Build Smart Books to facilitate preparation for briefings to the $A A E$ and DAE regarding the decision to build new in lieu of remanufacture. 
- Maintain a Smart Book that contains the latest position papers and key documents. Take the Smart Book with you to briefings so that when questions surface you will have access to key documentation that shows the full history.

- Hold IIPTs frequently enough to ensure that team members are kept up to date.

- Keep comprehensive minutes of the meetings, even if you simply record brief memos. Complete the notes soon after the meeting and get them staffed within the PM as soon as possible. Store the minutes where they can be found easily.

I Identify OSD subject matter experts early and establish good relations with them since they will help to streamline the process.

- PM IPT leads and leadership must make contact with DA and OSD staffers; this is particularly true in the documentation phases. If a document author stays engaged with the staffer, there will be fewer problems during documentation signoff.

Resource your staff. The DASC cannot do everything. You will be working on a contract and getting a milestone decision along with doing the day-to-day operations of creating a system. You must have the depth and breadth to accomplish these tasks concurrently. If you don't, you must either stretch your decision time or accept risk.

- Maintain healthy communication so that processes run smoothly. The PM and his staff must push the OSD and DA staff for concurrence and communication.

- Keep a record of each problem and how it was resolved; consider recording the information in a Smart Book. Carry this information with you so that if someone has a related question, you will be prepared to formulate an answer.

Stay in close communication with the G-8, Force Development and the G-3, Aviation Task Force. These groups are at the center of Army aviation and they will support you through the process.

Appoint an ASARC coordinator to serve as focal point in the $\mathrm{PM}$. This is the person who keeps a finger on the pulse of the program and ensures that the word gets to the DASC, the OSD AT\&L staff, and the DA ASARC secretary.
Lack of communication is a significant problem. For many reasons, the staff officer and his or her principal often do not communicate.

Information flow is fragmented across HQDA with disparate groups requiring their own unique information such as

- G-3, Information Requirements

- G-6, Acquisition Compliance and Certification

- G-6, Frequency Spectrum Division

- G-6, Architecture Operations Network and Space

Weekly telephone conferences with $\mathrm{PMO}$, DASC, Training and Doctrine Command (TRADOC) System Manager (TSM), ATEC proved to be helpful in terms of status document approvals and upcoming review coordination. 


\section{Lessons Learned Checklist}

Investigate having the Systems Engineering and Technical Assistance (SETA) contractor help you by providing

- facilities for use as a home base or meetings

- support in preparing items such as briefings and white papers

- backup information during the meeting or briefings

\section{Program Observations}

The SETA contractor is not always accepted by the DA and OSD staffs. The PM and his government staff are expected to know their program, maintain awareness of the issues, and be able to brief the program. AB3 coordinated DASC sponsorship for key SETA contracts; that enabled "no escort required" badges to be issued in the Pentagon.

Justifying and defending an extensive modernization program is highly complex and requires sound preplanning.

Because of the Net Ready KPP dependencies, JTRS program turmoil affected AB3 Milestone $B$ information and documentation processes. 


\subsection{Logistics and Support Lessons Learned}

The core depot analysis is a business case analysis to determine where depot-level repairables should be made.

The Manpower Estimate Report (MER) is used to help inform various manning decisions, cost estimates, and affordability of the program. (For more information about this, see Title 10 USC 2434, DODI 5000.2, DA PAM 70-3.) The entire process typically takes about eight months, but it might take longer if you are starting with a system that does not exist or one that will not replace an existing system.

Program managers are responsible for laying out and executing a strategic blueprint (i.e., Supportability Statement) for the logistics process so that every part of the package is integrated and contributes to the warfighter's mission capability.

AR 70-47 and DA PAM 70-3 require Transportability Reports to be conducted on all systems. These reports outline the assessment of the system's ability to be transported on the systems identified.

The system training plan (STRAP) — required by DoDD 1430.13, DoD 5000.2-R, and DA PAM 70-3 - describes how users will be trained on the system. The STRAP is generated by TRADOC and must be approved at TRADOC headquarters in conjunction with the requirements document.

\section{Lessons Learned Checklist}

Articulate all facts and assumptions clearly and use them consistently during the core analysis.

- Staff the initial draft of the supportability strategy as soon as possible within the Logistics IPT working group.

Update the basis of issue plan (BOIP) at every milestone.

\section{Program Observations}

Including performancebased logistics (PBL) requirements in all planned contracting efforts was critical.

Supportability/sustainment planning must be outlined by performance-based goals, metrics, and demonstrated progress.

It is essential to have contractor data for new items. The analyst must have the contractor's rationale and data for determining that the item is a depot-level repairable. If the contractor did not perform a level of repair analysis, he or she must make additional assumptions that increase the risk of error to the study. 
- Ensure that there are quantifiable supportability metrics for all phases of planning and execution.

OSD Logistics and Materiel Readiness (LM\&R) emphasized logistics planning and supportability.

Identify potential problems with getting the MER staffed and approved. It is often difficult to find someone who wants to own the MER.

Supportability was not an afterthought.

It was extremely difficult to get comments on the supportability statement.

systems engineering slide to include logistics supportability, and add a special interest item slide to include information about items such as corrosion prevention/control and unique identification.

- Communicate via the IPTs (e.g., telephone and email) that the document is forthcoming. This is key to successful staffing of the supportability statement.

$\square$ Coordinate the STRAP with all stakeholders to ensure that all data items are correct.

The STRAP is developed by the Directorate of Training, Doctrine and Simulation at United States Army Aviation Center (USAAVNC). The STRAP is not coordinated with the maintenance counterparts at the United States Army Aviation Center in Ft. Lee. Therefore, the maintainer training and training device information may not be correct.

- Coordinate logistics supportability documents with both the Secretary for Acquisition and Systems Management (SAAL) ILS and G-4 (Aviation Log Division). Examples of such documents are the AB3 supportability strategy report and the item unique identification plan.

Logistics supportability documents (e.g., the AB3 supportability strategy report and item unique identification plan) should be coordinated with the Deputy Assistant Secretary for Acquisition Policy and Logistics ILS and G-4 (Aviation Log Division). OSD LM\&R analysts are proactive once they receive these documents. 
- Adhere strictly to the total life-cycle systems management concept; this will lower the risks of sustainability. Developing a supportability plan early on and getting concurrence from the stakeholders is critical to operation and sustainment success.
It is no use to field a weapons system that is not supportable and sustainable. A supportable and sustainable system takes detailed planning up front and implementation throughout the life cycle. This is the intent of total life-cycle systems management concept.

Improved Block III supportability needed quantifiable metrics per OSD LM\&R. 


\subsection{Technical/Engineering Lessons Learned}

Joint Technical Architecture (JTA) is a common set of mandatory information technology standards (primarily interface standards) and guidelines. The JTA should be used by all emerging systems and systems upgrades, including advanced concept technology demonstrations. The JTA can be used to establish a system's technical architecture, and is applicable to all command, control, computing, communication, and intelligence (C4I) and automated information systems and interfaces of other key assets (e.g., weapons systems, sensory) with C4I systems.

The JCIDS process determines the requirements for the military, and as of March 2004, is governed by the Joint Chiefs of Staff Instruction (CJCSI) 3170.01C. The JCIDS document serves as the Operational Requirements Document (ORD) and answers the question "Why do you need the system?"

The Information Support Plan (ISP) strategy identifies the information technology (including national security systems) infrastructure enhancements that are required to support program execution. The ISP should identify technical, schedule, and funding issues that are in the critical path and that could affect the execution of the acquisition strategy in the infrastructure for the acquisition program and the information technology (including national security systems). The acquisition strategy then synopsizes the shortfalls and issues, and devises plans to resolve them.

\section{Lessons Learned Checklist}

Interface frequently with the Weapons Systems Technical Architecture Working Group JTA-A (WSTAWG/JTA-A); doing so will help you to resolve problems successfully.

\section{Program Observations}

The JTA mandate was relatively new during the initial development of the $\mathrm{UH}$ $60 \mathrm{M}$; many PMs struggled to understand the process by which the JTA-A compliance was to be demonstrated and who would eventually make the final determination of compliance. Through close partnership with other PMs and Aviation and Missile Command (AMCOM)/PEO assistance, and by having a good working relationship with the Army Systems Engineering Office (ASEO), these issues were eventually overcome and the process was successfully concluded.

Since the JTA-A is a living document, it is reviewed and modified periodically. Unfortunately the review process can have unintended effects. For example, during [this] program execution a specification sunset clause went into effect; the clause threatened to eliminate most of the legacy interface specifications used by Army aviation platforms. 
Lessons Learned Checklist

- Since the G-6 reviews are processed slowly, it is critical to maintain contact with someone in G-6 so that they can skillfully push the process along.

\section{Program Observations}

The compliance matrix and associated three waivers were submitted to ASEO for prescreening, before being submitted to G-6 for final approval. While ASEO was satisfied and assured the PMO that the documents were in good order and ready to be submitted, the G-6 review process was slow. This was due to an extensive backlog at G-6, which made it difficult to contact anyone and obtain meaningful status reports. The approval from G-6 took almost a full year and arrived just in time for the UH-60M Milestone $\mathrm{C}$ review.

Our ORD was delayed because of the requirement to include a Net Ready KPP and its associated pieces, which were dictated by CJCSI $6212.01 \mathrm{C}$ when it was implemented in 2004. This represented a significant change from the previous J-6 guidance, which indicated that because this was a new requirement, [the program] did not need to include it in the ORD. The change required us to develop a migration approach to meeting the KPP and develop architectures at TRADOC. This caused significant delays in the ORD approval process.

Apache Block III received invaluable program support review from NDI and OSD Assessments/Open Systems Architecture, Science and Technology. 


\subsection{Test and Evaluation Lessons Learned}

The purpose of the Test and Evaluation (T\&E) is to assess system progress toward operational effectiveness, suitability, and survivability. T\&E supports the system development and acquisition process, and is intended to provide information on risk identification and mitigation to Army decision makers. When considering a system's programmatic progress throughout its development life cycle and prior to major milestone decision reviews, risk must be accounted for (in concert with cost, schedule, performance, and supportability). Army programs are structured to integrate the developmental test (DT), operational test (OT), combined DT/OT, live fire test and evaluation (LFT\&E), system evaluation, and Modeling and Simulation (M\&S) as a continuum. (For more information about this, see DA PAM 73-1, Chapters 5 and 6.)

The System Evaluation Report (SER) is developed by the PM and presents the findings of the system assessment/test. The SER is required by DODI 5000.2 and provides the milestone decision authority assurance that the system is suitable, safe, and effective.

The MER is used to help determine manning decisions, cost estimates, and affordability of the program. The entire process typically takes about eight months, but could take longer if you are starting with a system that does not exist or one that will not replace an existing system. (For more information about this, see Title 10 USC 2434, DODI 5000.2, and DA PAM 70-3.)

\section{Lessons Learned Checklist}

Develop the SER early and be specific about the roles and responsibilities of the PMO and TRADOC.

\section{Program Observations}

It takes about three months for the SER to be completed following the end of testing. [The program] needed to talk generally [about] what ATEC does and, specifically, what [the program] did or should do to help the process. The real issue is reliability.

The TEMP is the key document used as a contract among all stakeholders in the evaluation process. Developing a TEMP must be a priority early in the program. Early involvement with the ATEC community is a key to success.

Assemble a T\&E WIPT charter early. The charter will help you to identify the organizations with which you should interface 


\section{Lessons Learned Checklist}

$\square$ Use Microsoft Word's track changes feature to coordinate updates. This will speed up the process while maintaining a record of the change history. Appoint one person to be responsible for consolidating changes and maintaining the current version.

- Make TEMP approval a priority. Most organizations require a specific time for staffing, and they will take their time based on the urgency. However, in the end, everyone will work to approve the TEMP to meet the DAB.

Understand the staffing process since there are many key documents that directly affect the TEMP (e.g., CDD, critical operational issues and criteria [COIC], systems threat assessment report).

- Maintain strict configuration control over the TEMP. Ensure that everyone involved has the latest version. This is critical because the TEMP requires several updates as it evolves.

$\square \quad$ Facilitate approval of the key documents as required. Make sure the documents are approved prior to formal TEMP staffing through DA.

As soon as the program is established, it is critical to identify - an ATEC system team chair from the Army Evaluation Center

- a developmental test lead from Developmental Test Command - an operational test lead from Operational Test Command

$\square$ Work closely with the TSM in CDD development and the COIC process. Do a requirements crosswalk to test the program to assure that everything has been addressed.

Maintain close coordination with the TSM. This will help to ensure that the test program addresses the users' needs.

\section{Program Observations}

during the development of the TEMP.

Since there are many key documents that directly affect the TEMP (e.g., CDD, critical operational issues and criteria [COIC], systems threat assessment report), it is important to understand the staffing process. 


\subsection{Source Selection and Evaluation Lessons Learned-Attack Reconnaissance Helicopter (ARH)}

Planning for the Source Selection Evaluation Board (SSEB) was initiated in mid-October 2004 with an SSEB start of January 2005. Planning consisted of identifying personnel and logistics requirements and developing training media. Multiple in-process reviews were held internally within the SSEB management team to ensure that the plans were sound. The plans were briefed to the Source Selection Advisory Council (SSAC) chairman approximately two weeks prior to the SSEB start to obtain approval.

After the requirements were established and approved, coordination was initiated with the AMCOM Acquisition Center Facilities POC to obtain appropriate facilities for the team. Between November 2004 and early January 2005, four initial training sessions were conducted. The goal of these meetings was to provide to all board members information about (1) the Army Source Selection Guide, (2) the source selection plan, (3) the modified process, and (4) the schedule.

Three days prior to receiving the proposals from offerors, follow-on (secondary) training was provided to all SSEB members. This training detailed the milestones/schedule and the database system. A "rock drill" on the database concluded this training event and prepared the team for proposal receipt.

One set of offerors' discussions was conducted by telephone and two discussions were conducted in person. All discussions were audiotaped and/or videotaped.

The organizational leadership structure of the SSEB included a chairman; deputy; operations officer and staff; and factor, sub-factor, and element leads. Normally, an operations officer is not utilized in an SSEB; however, due to the size and complexity of this particular SSEB, it was determined that full-time work was required to manage personnel, logistics, and day-to-day and future operations of the SSEB proceedings. Additionally, having an operations cell allowed the chairman and deputy to be more involved in the technical aspects of evaluations with the procurement contracting officer and legal advisor.

The source selection plan was approved by the Source Selection Authority (SSA) in November 2004. The SSEB chairman was brought into the planning in mid-October - in the middle of the draft request for proposal (RFP) process - and was immediately involved in the revisions of the source selection plan. Additionally, the chairman served as a primary briefer to the SSA to obtain approval of the selection plan.

\section{Lessons Learned Checklist}

Obtain written authorization to use the Redstone Arsenal facilities and ensure that the director or deputy director, Acquisition Center, provides approval. Ensure that there is significant time (two to three months) between when one SSEB concludes and another one begins.

\section{Program Observations}

The institution of a full-time operations center for the SSEB increased efficiency in the current and future operations of the process.

Physical security was maintained in the building by a code (cipher) lock and a sepa- 


\section{Lessons Learned Checklist}

Form SSEB organizational structures that provide the appropriate additional staff to manage personnel, logistics, and operations.

Provide facility/building drawings that detail the requirements of each room in terms of computers, local area network drops, phones, tables, chairs, and other furnishings. Do this at least three months ahead of time so that any necessary work can be completed on time.

D Devise a physical security plan to ensure that only SSEB personnel have access to the SSEB facility.

a Physically relocate the SSEB chairperson to the PM office prior to the last revision (at least one month prior to planned approval) of the source selection plan. This will provide a "sanity" look into the plan that the SSEB inherits from the PM office. This will also help to get buy-in from the SSEB lead since he or she will personally be involved in the revision process.

- Ensure that the SSEB chairman is involved with any revisions that are made to the SSP.

Ensure that the installation (AMCOM) has an inhouse contract for managing a standardized Microsoft Access database (government owned) for use by all SSEBs on servers in all special studies buildings.

\section{Program Observations}

rate key lock on the outer entrance/exit door. The code was given to all evaluators and above; factor leads and the SSEB management had keys to the secondary lock. During normal business hours, the secondary lock was unlocked to allow SSEB members to travel freely. This ensured that non-SSEB personnel did not gain access to the building.
The SSEB chairman's one-month involvement with revisions of the source selection plan provided a positive transition from the ARH business division to the SSEB management control.

An Army-owned standardized "user-friendly" database is required to store SSEB evaluation, element, sub-factor, and factor-level rollup consensus data.

There were no standardized digital/computer SSEB databases offered by the government for use in facilities to properly store the data from evaluations. The SSEB management team coordinated with SAIC Inc. to view the "Auto-SSEB" program, which has been the only database system used on Redstone Arsenal by SSEBs. The Auto-SSEB system is 10 years old; it would cost about $\$ 75,000$ to modify the software and gain two weeks of contract support. [The program] ultimately tasked a TSM-Recon/Attack support contractor (an individual with immense software development knowledge) to develop and maintain a Microsoft Access database. This cost the government in man-hours just a fraction of what the Auto-SSEB software would have cost. 


\section{Lessons Learned Checklist}

Initiate a Memorandum of Agreement (MOA) for all organizations that provide personnel to the SSEB. The MOA should lock-in the personnel so they are not be removed from the board.

\section{Program Observations}

Ensure that all personnel comprising an SSEB are approved in writing by the home organization and that they are not allowed to be removed from the board. Valuable time is lost in training new personnel midstream in an evaluation, and disruption of the SSEB schedule can occur.

The acquisition center leadership removed the cost factor lead two months into the program SSEB and provided a replacement factor lead. Because of this disruption, the most probable cost had to be completed by an advisor to the SSEB; the cost evaluation took an extra three days to complete as per the SSEB internal schedule.

An intra-building email system should be attained to gain efficiencies for SSEBs. Since we did not have such a system, valuable time was lost because SSEB members had to physically walk from one room to another to communicate. Additionally, the Directorate of Information Management should appoint an individual who is trained to set up and maintain the email system.

The government must direct offerors to utilize a standard communication medium to process information back to the government. Offeror-owned websites were not reliable for time-sensitive EOC.

To ensure that the area is free of nonauthorized personnel, it is paramount to use a cipher lock system on any main entrance/exit at an SSEB facility.

It was difficult to schedule the source selection plan, mid-point brief, and final briefings for the SSA/SSAC advisors because general officer/senior executive service schedules conflicted with the evaluation timeline. Also due to scheduling conflicts, the midpoint brief was "pushed to the right" five days. This affected the contract award by the same number of days. 


\section{Lessons Learned Checklist}

- Develop a process that mandates how offerors' responses to the EOC will be transmitted back to the government for processing.

\section{Program Observations}

The SSEB did not mandate to the offerors how responses to EOC would be transmitted back to the government after processing. Offerors usually provided EOC responses via unclassified email, but one offeror requested the SSEB to utilize their internal website. In some instances, the website had internal faults and the contract specialist experienced delays in receiving timely information. This slowed the review process of the SSEB management team. 


\title{
Appendix A: Longbow Apache Overview
}

\author{
After Action Report (AAR) \\ Longbow Apache Block III Acquisition \\ 2004-2006
}

\section{Purpose}

Provide lessons learned on Apache Block III (AB3) program actions leading up to Milestone B DAB approval allowing entry into the System Development and Demonstration (SDD) phase.

\section{Overview}

This AAR focuses on lessons learned over a two-year period with emphasis on the intensive efforts exerted by representatives from the ASA(ALT) Department of the Army System Coordinator (DASC) in SAAL-SAI; G-3, G-4, G-6, G-8, Deputy Assistant Secretary of the Army for Cost and Economics (DASA-CE), ATEC, Training and Doctrine Command (TRADOC) System Manager (TSM) - Reconnaissance/Attack and the Apache Attack Helicopter (AAH) Project Manager's Office (AAH-PMO).

As the requirements and materiel solution evolved, it then brought in respective subject matter experts from the various OSD offices including Acquisition Technology \& Logistics (AT\&L) Land Warfare; Comptroller; Deputy Director for Research \& Engineering (DDRE); Program Analysis \& Evaluation (PAE including Cost Analysis Improvement Group (CAIG)); Director, Operational Test \& Evaluation (DOTE); Office of General Counsel (OGC); Acquisition Resources \& Analysis (ARA); Logistics \& Materiel Readiness (L\&MR); Science \& Technology (S\&T); Defense Policy And Procurement (DPAP), JCS J-8, and National Geospatial Intelligence Agency (NIMA).

The campaign to achieve an approved Milestone B Decision Review on 28 June 2006 by the Defense Acquisition Board began in earnest in early 2004, when the previous AAH-PMO planted the initial seeds to HQDA leadership via a series of briefings informing numerous General Officers of the need for a technological improved AH-64D Longbow AB3 over the next 25 years. Over 26 tech insertions are envisioned for the AB3 to improve interoperability, survivability and lethality over the current Longbow Apache Block II configuration. In concert with justifying a material solution to the Army Secretariat side of HQDA was the need for an $\mathrm{AB} 3$ requirements definition by the TRADOC community (TSM for Recon/Attack and HQ TRADOC Combat Developments and Futures). The AB3 requirements process began initially as an Operational Requirements Document (ORD) in early 2004 and evolved into a CDD approved by both the Army Requirements Oversight Council (AROC) and Joint Capabilities Board (JCB) using the recent applicable JCIDS process culminating with a JROCM on 3 June 2006. The AB3 ORD to CDD conversion and the associated approval/validation process precipitated numerous FCB/JCB/JROC briefings. 


\title{
Appendix B: Armed Reconnaissance Helicopter Overview
}

\author{
Extract from Milestone B After Action Report for the Armed Reconnaissance \\ Helicopter Program \\ December 2005
}

\section{The Process}

Despite the many urban myths, the fundamental acquisition process works fairly well overall. It provides a good cross leveling and cross checking of all aspects of the program to ensure that the correct approach is being used to support the war fight. That is not to say that additional acquisition streamlining is not necessary.

There are three embedded activities as you go for acceleration: the JCIDS, acquisition, and contracting pieces. Each activity is separate and unique and has its own requirements. PMs must make sure that they have a primary contact leading each effort. For the JCIDS process, it is the Training and Doctrine Command (TRADOC) System Manager (TSM). For the acquisition process, it is the PM. For the contracting process, it is the PM plus the Aviation and Missile Command (AMCOM) Contracting Office support. PMs must track those three activities in parallel and make sure they stay in lock step. However, it is important to understand that all parts of the process move at different speeds and not all parts of the process are treated with equal priority and equal effort. Therefore, you have to balance those priorities as you go forward in terms of scheduling meetings; consider when the meetings will take place and who should attend them. While it is important to understand your parochial point of view as a PM, you certainly need to understand the other priorities. For example, as you go through the process, it is not enough to understand just your program; you have to understand the impact of your program with other Army and OSD programs.

As well as the historical execution of programs within the Army in general, programs are held accountable to both the good and bad program execution of the past. The Army may give up something on your particular program in order to support a strategic decision to get OSD support across many areas. In our program, the Army consciously did not fight several decisions because there were three other new-start programs coming through the same process and they did not want to lose the ability to maintain the moral high ground as the other programs came through. It is important that you realize the impact of what you are giving up and its relationship to the program.

Moving through the process, is critical that PMs understand that there are no shortcuts. Every program is different, but the fundamental starting place for all programs is that they understand your ACAT level and what the law says you must do and what your Milestone Decision Authority (MDA) will accept. The items that are required by law are very hard to waive. Some programs may indicate that they "skipped" steps in the process, but in most cases, you will find that they had a "due-back" or had to do it after the milestone decision. 
For most programs, PMs choose and embrace the process of getting to the milestone decision. Understand early, via the ASARC secretary and through the OSD DAB secretary, what is required and what the MDA expects. You can then focus on what the MDA needs by working through the Integrating Integrated Product Team (IIPT) process. The IIPT process is not going to let you by-pass what needs to be done. So rather than try to fight that, it is important that you embrace it and put the assets in your own organization in place to do that.

\section{Consistency}

As you go through the process, it is critical to make sure that you have a consistent approach in terms of briefings, meeting formats, and strategy. Doing this saves time and helps you to avoid repeating problems.

Using a set of consistently formatted meetings and slides is beneficial since everyone will be accustomed to seeing the logistics information, programmatic information, milestones, and funding information in this consistent way. Use this fundamental set of slides to maximize success in the process.

We used the Smart Book approach. We started with a set of slides that we consistently used as the foundation as we went forward. That set the conditions for all the Army IIPTs, the OSD IIPTs, Overarching Integrated Product Teams (OIPT), ASARCs, and DABs.

\section{Documentation}

It is important to understand the start-point and end-point of each document in the process. We created a matrix of who was tasked to write each document, who was assigned to review each document at every step, where each document stopped, and where it needed to continue. Not all Milestone B documents are OSD documents, some stop at the Army. Understand where you begin and end in each step of the process and make sure your people have that information as you go forward.

The organization in the Milestone B preparation period needs to be adaptive and proactive in the process. In so doing, a smaller office provides the ability to do several key tasks.

First, as you move forward, coordinate the 37 Milestone B documents. This includes the business section, the technical section, the logistical section, and the acquisition section, each of which will move at a different speed.

Next, appoint a single point of contact in the office to track the milestone documents. Traditionally, program offices have hired contractors to write these documents. We elected not to do that because we wanted the people who were going to execute the program to write the documents. That turned out to be a valuable asset since everyone knew one another and understood the processes; additionally, this group of people exercised the decision process during the SDD period of the program. 
This last piece of the organization is in support of the Life Cycle Management Center (LCMC) concept. Personnel were co-located in our office with our 14 Table of Distribution and Allowances (TDA) positions and 2 additional military positions for a total of 16 TDA positions. Combined with key players in the community, representatives from the following organizations teamed with the TSM to write the documents.

- Army Test and Evaluation Command (ATEC)

- Aviation Engineering Directorate (AED)

- Integrated Material Management Center (IMMC)

- Safety Center, Configuration Control, Software 


\title{
Appendix C: UH-60M Black Hawk Executive Summary
}

\author{
UH-60M BLACK HAWK Modernization Program \\ Milestone $C$ \\ After Action Report
}

\section{Executive Summary}

The UH-60M Modernization Program conducted its Milestone $\mathrm{C}$ preparation during the winter of 2004-2005. This effort culminated in a Defense Acquisition Board (DAB) briefing on 15 March 2005 and a signed Acquisition Strategy and Acquisition Decision Memorandum on 31 March 2005.

During the course of these events, we attempted to follow the processes that are outlined in the DoD 5000 series, the Defense Acquisition Guidebook, and Army, OSD, and Joint Staff guidance documents.

We found that in many cases the documented processes and procedures are not always understood by the staffs, may not be followed, and sometimes, do not meet the requirements of real-life situations.

Among the greatest issues we encountered was how to deal with the UH-60M Upgrade program, lack of communication between the decision makers and staffers and subsequently the PM, and interaction between staffers and their principals.

The PMO tried to keep the UH-60M Upgrade program from influencing the UH-60M Milestone decision. The PM, very early in the game said they would be willing to treat it as a separate program. However, the OSD staff wanted to tie the two programs together and the Office of the General Counsel (OGC), the Comptroller, and AT\&L Policy could not figure out how to execute the Upgrade program in light of what the 5000 series program advocated. Throughout these processes, the PM spent more time and effort on the Upgrade program than it did on the baseline production decision.

Compounding this problem was a lack of decision authority guidance. In November, OSD AT\&L Systems and Policy, OGC, and Comptroller directed a course of action for Milestone C including how to handle the Upgrade program. Two days prior to the OIPT, the director of Defense Systems, was pre-briefed by his staff and said he would not buy into the proposed strategy. Thus, three months of effort was altered because the staff had not communicated to their boss and received his intent.

The PM also found that the staff principals were not well informed about the program and additional one-on-one briefings were required. These briefings, in the author's opinion, were instrumental in resolving issues that languished at the staff level. While the AAE and DAE may not think such briefings are unnecessary, we found they are absolutely essential. 
This after action report provides input about how the UH-60M Modernization Product Office accomplished the milestone decision process. It includes a resume on the actions taken to develop, staff, and obtain approval for each document. It contains the documents, the decision briefings and the IIIPT briefings. It furnishes issues we encountered and provides recommendations regarding the actual process to follow.

The opinions contained are those of the people who accomplished the effort and do not necessarily reflect those of the Department of the Army or the Department of Defense.

Robert H. Lunn

Lieutenant Colonel, U.S. Army

Product Manager, UH-60M 


\title{
Appendix D: Raven Unmanned Aerial System AT\&L Article: "Acquisition in the Fast Lane-The Small Unmanned Aerial Vehicle (SUAV) Product Office"
}

\author{
By William R. (Bobby) Ellis, Jr. \\ Note from the authors: We include this article here since it accurately \\ represents the experiences of a typical product manager, and best \\ characterizes rapid acquisition and rapid fielding choices. ${ }^{3}$
}

The Raven (RQ-11B) Small Unmanned Aerial Vehicle (SUAV) offers a compelling story of rapid response to urgent theater needs. The SUAV Product Office (PO) moved from an initial capability, demonstrated through a Rapid Fielding Initiative, to Full Rate Production (FRP) in less than fifteen months. Included in that short time span were full and open competition for source selection, Milestone C-Low Rate Initial Production (LRIP) decision, Initial Operational Test and Evaluation (IOT\&E), and finally an FRP decision. The culminating event was First Unit Equipped in fifteen months! Although accomplished in a relatively short time span for an acquisition Program of Record, there were numerous obstacles that had to be overcome to achieve this aggressive schedule.

\section{Obstacles}

The SUAV was widely accepted as essential to the commander's needs in the Global War on Terrorism, which provided the impetus for rapid acquisition. Over the course of the fifteen months, the SUAV team achieved important objectives. The team also overcame major obstacles such as:

- $\quad$ stood up the SUAV PO

- supported development and staffing requirements

- completed source selection

- $\quad$ established program elements (PE) for Research Development Test and Evaluation (RDT\&E) Funding and Operational Maintenance Account (OMA) funding

- planned and executed an IOT\&E, including replacing the scheduled test unit with less than 60 days before test start date

- lost 50\% of FY07 funding and 25\% of FY10 funding

The SUAV PO simultaneously supported the SUAV Rapid Equipping Force Initiative systems in Operation Iraqi Freedom (OIF) and Operation Enduring Freedom (OEF); integrated requirements from Special Operations Command (SOCOM) and the Marine Corps; and became a program of Joint Interest and Funding.

Reprinted with permission from Army AL\&T. The article originally appeared in the July-September 2007 issue of Army AL\&T Magazine

(http://asc.army.mil/altmag/default_previous.cfm?issueYear=2007\&issueMonth=3_JulAugSept). 


\section{The Right People}

In June 2005, the Unmanned Aircraft Systems (UAS) Project Manager decided to break the SUAV Program of Record out of the Ground Maneuver PO and create a separate SUAV PO. Three personnel from Ground Maneuver transferred to SUAV. A non-board-selected Product Manager (PM) and a deputy were hired to execute the program and constitute the office. Their first act was to assemble the necessary personnel to staff the new PO. Experience and maturity were key qualifiers for individual team members. A hybrid organization was created and staffed with personnel from within the Aviation and Missile Command (AMCOM). The organization consisted of the PM and deputy, a small core of matrix personnel from the AMCOM functional elements, business management from the parent UAS Project Office, and supporting contractor personnel. The goal was to keep the organization as small as possible while allowing all the functional areas to be covered (e.g., program management, engineering, logistics, and business). Eight months into the execution of the program, the staff numbered thirty personnel. The team members shared several key traits: a driven desire and focus on supporting the soldier, an ability to multitask, a mature demeanor, ten plus years experience in their functional areas, and a willingness to work long hours and travel. The SUAV PMO paid a premium price to capture its staff; however, by focusing on the higher percentile personnel, the PMO was able to perform as a program office from the onset. Everyone in the PO was expected to work outside his or her normal functional areas to support the entire team.

\section{Source Selection}

The Source Selection Board for the SUAV began on 5 June 2005. Seven vendors provided proposals for evaluation. Source selection consisted of the following six phases.

1. solicitation and receipt of proposals

2. questions and answers

3. paper down-selection to two vendors

4. fly-off of the two competitors

5. best and final proposal

6. vendor selection

An immediate issue arose as most competitors were small businesses and needed additional time to develop proposals. After the down-select to two contractors, Hurricane Katrina hit the Gulf coast. One vendor requested and received a delay in accomplishing the fly-off because of their participation in the relief assistance to New Orleans. This situation, combined with delays in source selection, slipped Milestone $\mathrm{C}$ and contract award for LRIP by two months, to October 2005. Funding for the LRIP systems was thus jeopardized, having originated from FY04 Comanche RDT\&E and would expire at the end of September 2005. To prevent further schedule slippage, PM UAS internally reprogrammed funding from SUAV to other UAS programs. The SUAV program received replacement RDT\&E funding from reprogramming of FY05 and FY06 UAS programs. Most importantly, while the SUAV overall program slipped, the IOT\&E scheduled for June 2006 did not. 


\section{Programmatics}

The SUAV program was established with a single PE budget line for procurement. The PM SUAV took action to establish PEs for both RDT\&E and OMA. This required close cooperation with Army G8 and the Army Budget Office (ABO). The Army established the necessary budget lines for FY08 and beyond. This action was time consuming with repeated trips to Washington, D.C. to brief the G8 and ABO personnel. The time spent with these offices secured champions for the SUAV program during Program Objective Memorandum (POM) development activity. The key to a positive outcome for the SUAV PMO was daily contact with key personnel and offices within the Pentagon.

\section{Test and Evaluation}

Originally, the SUAV IOT\&E was scheduled for June 2006. In late November 2005, the designated test unit was alerted that they would deploy early and not be available for IOT\&E. This was a devastating blow to the SUAV program. Due to the Global War on Terrorism (GWOT) and unit rotations, no replacement unit would be unavailable until March 2007, at the earliest. This caused Army G8 and G3 to redirect SUAV funding to cover other Army requirements by decrementing the FY07 SUAV Budget by $50 \%$ and the FY10 SUAV budget by $25 \%$. To maintain program schedule for production and fielding, the SUAV PM began directly contacting units to provide the necessary forces to accomplish the IOT\&E. The following three possible courses of action arose.

- Units from the $2^{\text {nd }}$ Infantry Division (ID) in Korea agreed to support IOT\&E. The logistical considerations to make this happen, although staggering, were not impossible to meet. Additional funding over the original planned cost for the IOT\&E was required. A critical hurdle appeared when the Korean frequency manager disapproved the downlink frequency, which would require a costly hardware reconfiguration. However, the Army Test and Evaluation Command (ATEC) objected since the new configuration would not be production representative. Another possibility was to move the test unit to a location where SUAV frequencies were approved for use. All of the objections for the $2^{\text {nd }}$ ID were surmountable but were not the best solution due to additional funding and the logistical implications.

- The United States Marine Corps (USMC) was considered as a potential test unit; however, their Tactics, Techniques, and Procedures (TTPs) were not the same as Army Infantry. The PM decided to continue to pursue this course of action while giving the Army one last chance to provide the unit for IOT\&E.

- The PO contacted Army units that had used the previous version of SUAV, Raven-A, in the GWOT. As the Raven-B had won the competition for the SUAV, these units were generally familiar with the capabilities of the system. One unit, the $1^{\text {st }}$ Cavalry Division (CAV) in Ft Hood, Texas, was very receptive to supporting IOT\&E if the unit under test would become the first equipped. All parties, including the test community, eventually agreed to this course of action.

The $4^{\text {th }}$ Brigade Combat Team (BCT), $1^{\text {st }}$ CAV, Fort Bliss, Texas would support the IOT\&E test using the combined facilities of Fort Bliss and White Sands Missile Range. This allowed the program schedule to remain unchanged for IOT\&E in June 2006. The commander, staff, and soldiers of the $4^{\text {th }}$ BCT gave a collective herculean effort to ensure success. They accomplished the task 
concurrent with new unit staffing, equipping, training and preparation for a rotation to the National Training Center and deployment to theater within two months of the scheduled end of IOT\&E. In many ways they were the critical "nail in the horseshoe" leading to the eventual fielding on Raven-B to the Army.

\section{Success}

There were many challenges for the SUAV program to overcome. Success required that the office address all the obstacles of the acquisition process, funding, and test and evaluation. The following tenets helped the PMO achieve success.

- Select the right people (i.e., the most valuable resources).

- Never give up.

- Think outside of the box.

- Remember that "no" is not the final answer (i.e., remember to rethink the question).

- Solicit senior leaders to become champions of the program (i.e., conduct information flow).

- Work with and help organizations understand the validity of your system (e.g., ABO, G8, G3, etc.).

- Make reasonable demands (i.e., don't ask for the moon).

- Link the program to other services (e.g., powerful stakeholders).

- Use this rule: "If it is in someone else's lane and they can't do it...do it yourself!"

These tenants are not new; however, by being aggressive in their application, the SUAV program was able to overcome its challenges. A successful IOT\&E maintained the original timeline and resulted in a positive report from both ATEC and the Director, Operational Test and Evaluation. This led to plus-ups in the budget for the SUAV program. Fortunately, all lost funds were recovered in the POM-build process.

In short, the SUAV PMO has been able to react to early demands for fielding and training of units for the Raven-B SUAV. SOCOM and the Marine Corps were fielded Raven-B ahead of schedule. UAS requirements from commanders in the field are growing exponentially and the PO continues to exceed the demands placed on it for SUAV systems by meeting the soldier's needs.

\section{About the Author}

Mr. William (Bobby) Ellis, Jr. is the product director for Small Unmanned Aerial Vehicle Systems within the U.S. Army Unmanned Aircraft Systems Project Office. He is also a Lt. Col. in the Army National Guard. 


\section{Appendix E: Acronyms}

\section{AAE}

Army Acquisition Executive

\section{AAH}

Apache Attack Helicopter

AAR

After Action Review

AB3

Apache Block III

ABO

Army Budget Office

\section{ACAT}

Acquisition Category

ACP

Army Cost Position

ADM

Acquisition Decision Memorandum

AED

Aviation Engineering Directorate

\section{AMCOM}

Aviation and Missile Command

AoA

Analysis of Alternatives

\section{APB}

Acquisition Program Baseline

AR

Army Regulation

\section{ARA}

Acquisition Resources \& Analysis

\section{ARH}

Armed Reconnaissance Helicopter 
AROC

Army Requirements Oversight Council

ASA(ALT)

Assistant Secretary of the Army (Acquisition, Logistics, and Technology)

ASARC

Army Systems Acquisition Review Council

ASEO

Army Systems Engineering Office

ASR

Acquisition Strategy Report

AT\&L

Acquisition Technology \& Logistics

ATEC

Army Test and Evaluation Command

BCT

Brigade Combat Team

BOIP

Basis of Issue Plan

C4I

Command, Control, Computing, Communication, and Intelligence

\section{CAIG}

Cost Analysis Improvement Group

CARD

Cost Analysis Requirements Document

\section{CAV}

Cavalry Division

CCA

Component Cost Analysis

CDD

Capability Development Document

\section{CJCSI}

Joint Chiefs of Staff Instruction 


\section{COIC}

Critical Operational Issues and Criteria

\section{CRB}

Cost Review Board

\section{DA}

Department of the Army

\section{DAB}

Defense Acquisition Board

\section{DAE}

Defense Acquisition Executive

\section{DASA-CE}

Deputy Assistant Secretary of the Army for Cost and Economics

\section{DASC}

Department of the Army Staff Coordinator

\section{DDRE}

Deputy Director for Research \& Engineering

\section{DoD}

Department of Defense

\section{DOT\&E}

Director, Operational Test and Evaluation

DPAP

Defense Policy And Procurement

DT

Developmental Test

\section{DUSA-OR}

Deputy Under Secretary of the Army for Operations Research

EOC

Early Operational Capability

FRP

Full-Rate Production

GWOT

Global War on Terrorism 


\section{HQDA}

Headquarters, Department of the Army

ICE

Independent Cost Estimate

ID

Infantry Division

IIPT

Integrating Integrated Product Team

IMMC

Integrated Material Management Center

IOT\&E

Initial Operational Test and Evaluation

IPT

Integrated Product Team

ISP

Information Support Plan

ITAB

Information Technology Acquisition Board

JCB

Joint Chiefs of Staff Functional Capabilities Board

JCIDS

Joint Capabilities Integration and Development System

JROC

Joint Requirements Oversight Council

JROCM

Joint Requirements Oversight Council memorandum

JTA

Joint Technical Architecture

JTRS

Joint Tactical Radio System

KPP

Key Performance Parameter 


\section{LCMC}

Life Cycle Management Center

\section{LFT\&E}

Live Fire Test and Evaluation

\section{LM\&R}

Logistics and Materiel Readiness

\section{LRIP}

Low Rate Initial Production

M\&S

Modeling and Simulation

\section{MDA}

Milestone Decision Authority

MEP

Mission Equipment Package

MER

Manpower Estimate Report

MILDEP

Military Department

\section{MOA}

Memorandum of Agreement

\section{NIMA}

National Geospatial Intelligence Agency

\section{O\&S}

Operation and Support

OEF

Operation Enduring Freedom

OGC

Office of General Counsel

OIF

Operation Iraqi Freedom

OIPT

Overarching Integrated Product Team 


\section{OMA}

Operational Maintenance Account

ORD

Operational Requirements Document

OSD

Office of the Secretary of Defense

OT

Operational Test

\section{PAE}

Program Analysis and Evaluation

PBL

Performance-Based Logistics

PE

Program Element

PEO

Program Executive Office

PM

Product Manager

\section{PMO}

Program Management Office

PO

Product Office

POC

Point of Contact

POE

Program Office Estimate

POM

program objective memorandum

\section{RDT\&E}

Research Development Test and Evaluation

\section{RFP}

Request for Technology 
S\&T

Science \& Technology

SAAL

Secretary, Acquisition and Systems Management

SDD

System Development Demonstration

SEP

System Engineering Plan

SER

System Evaluation Report

SETA

Systems Engineering and Technical Assistance

SOcom

Special Operations Command

\section{SSA}

Source Selection Authority

SSAC

Source Selection Advisory Council

\section{SSEB}

Source Selection Evaluation Board

\section{STRAP}

System Training Plan

SUAV

Small Unmanned Aerial Vehicle

\section{T\&E}

Test and Evaluation

\section{TDA}

Table of Distribution and Allowances

\section{TEMP}

Test and Evaluation Master Plan

\section{TRA}

Technology Readiness Assessment 


\section{TRADOC}

Training and Doctrine Command

\section{TSM}

TRADOC System Manager

TTP

Tactics, Techniques, and Procedures

\section{UAS}

Unmanned Aircraft System

USAAVNC

United States Army Aviation Center

\section{USMC}

United States Marine Corps

\section{WIPT}

Working Integrated Product Team

\section{WSTAWG}

Weapons Systems Technical Architecture Working Group 


\section{REPORT DOCUMENTATION PAGE}

Form Approved

OMB No. 0704-0188

Public reporting burden for this collection of information is estimated to average 1 hour per response, including the time for reviewing instructions, searching existing data sources, gathering and maintaining the data needed, and completing and reviewing the collection of information. Send comments regarding this burden estimate or any other aspect of this collection of information, including suggestions for reducing this burden, to Washington Headquarters Services, Directorate for information Operations and Reports, 1215 Jefferson Davis Highway, Suite 1204, Arlington, VA 22202-4302, and to the Office of Management and Budget, Paperwork Reduction Project (0704-0188), Washington, DC 20503.

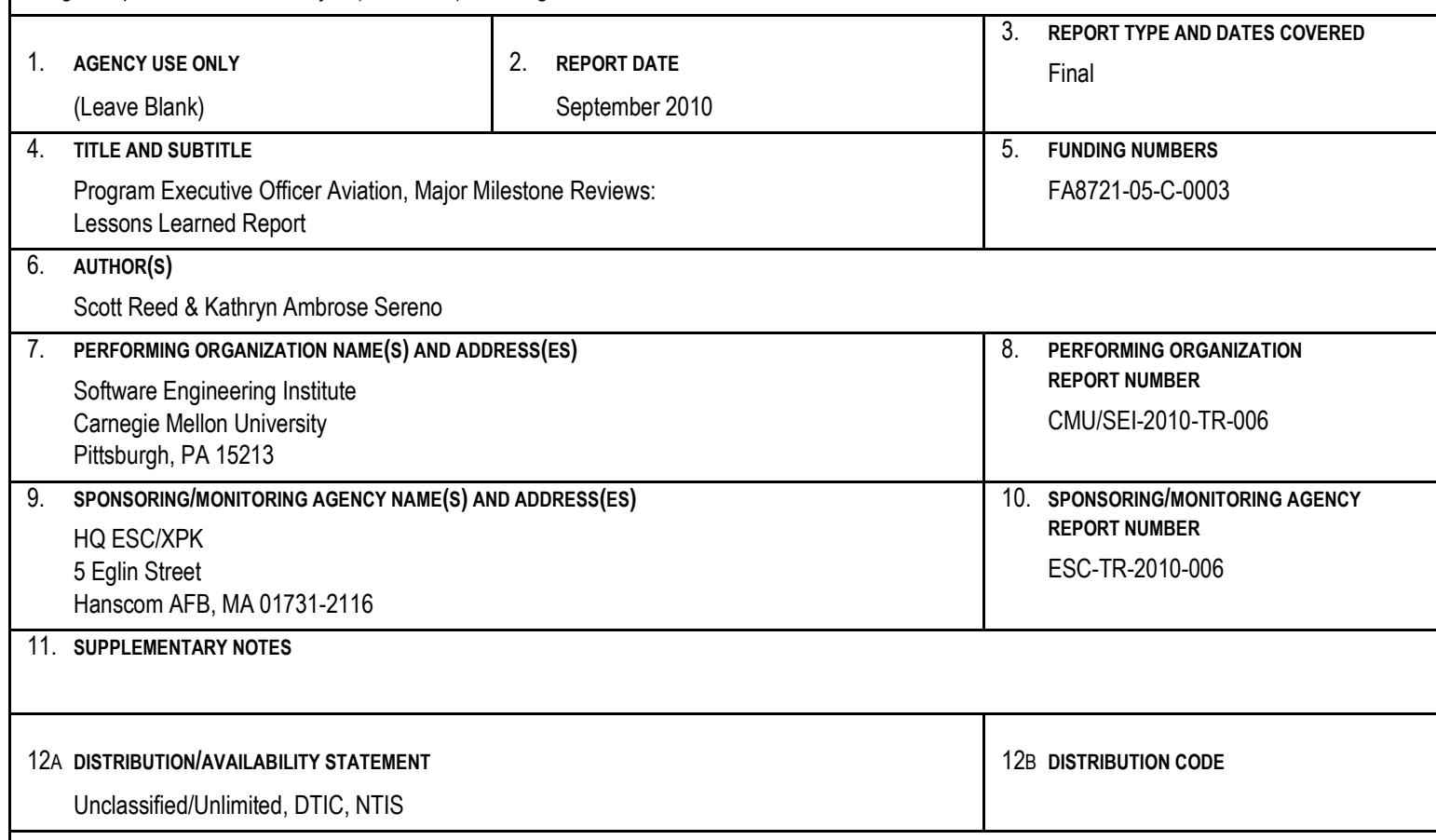

\section{ABSTRACT (MAXIMUM 200 WORDS)}

This report documents ideas and recommendations for improving the overall acquisition process and presents the actions taken by project managers in several programs to develop, staff, and obtain approval for their systems. This report contains information on the decision briefings and lessons learned, and describes issues encountered and the recommendations regarding the actual processes that were followed. Finally, this report includes checklists of required actions that will assist new and existing Program Management Offices (PMOs) as they prepare for milestone reviews.

\section{SUBJECT TERMS}

acquisition, lessons learned, ACAT programs, systems engineering, Program Management Office, $\mathrm{PMO}$

16. PRICE CODE

\section{NUMBER OF PAGES}

54

\begin{tabular}{|l|c|c|c|}
\hline $\begin{array}{l}\text { 17. SECURITY CLASSIFICATION OF } \\
\text { REPORT }\end{array}$ & $\begin{array}{l}\text { 18. SECURITY CLASSIFICATION } \\
\text { OF THIS PAGE }\end{array}$ & 19. SECURITY CLASSIFICATION & 20. LIMITATION OF ABSTRACT \\
Unclassified & Unclassified & OF ABSTRACT & UL \\
\hline
\end{tabular}


